\title{
The role of statins as therapeutic agents in cancer
}

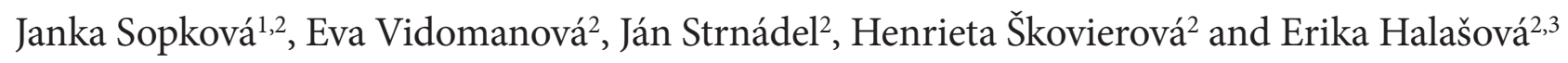 \\ ${ }^{1}$ Department of Medical Biochemistry, Jessenius Faculty of Medicine in Martin, Comenius University in Bratislava, Martin, \\ Slovakia \\ ${ }^{2}$ Biomedical Center Martin, Jessenius Faculty of Medicine in Martin, Comenius University in Bratislava, Martin, Slovakia \\ ${ }^{3}$ Department of Medical Biology, Jessenius Faculty of Medicine in Martin, Comenius University in Bratislava, Martin, Slovakia
}

\begin{abstract}
Statins are the inhibitors of 3-hydroxy-3-methylglutaryl coenzyme A (HMG-CoA) reductase. This enzyme catalyzes conversion of HMG-CoA to mevalonate, which are the intermediates in cholesterol biosynthetic pathway. Statins also play an important role in carcinogenesis, because they are able to affect the cancer cell metabolism. Their effect has been observed in several cellular processes, such as angiogenesis, metastasis, apoptosis and cell proliferation. However, these effects are highly dependent on type of cancer and individual statins vary in their antitumor potential. This review summarizes the recent epidemiological evidence and preclinical studies that showed effects of all clinically used statins in vitro and in vivo. We also consider the results of different observational and retrospective studies focused on association among statins and cancer risk which are still under open discussion.
\end{abstract}

Key words: Statins - Cancer - Mevalonate pathway - Cholesterol

\begin{abstract}
Abbreviations: AML, acute myelogenous leukemia; Bcl-2, B-cell lymphoma protein 2; COPD, chronic obstructive pulmonary disease; CVD, cardiovascular disease; ERK, extracellular signal-regulated kinase; FPP, farnesyl pyrophosphate; GGPP, geranylgeranyl pyrophosphate; HMG-CoA, 3-hydroxy3-methylglutaryl coenzyme A; LDL, low-density lipoprotein; MEK, mitogen-activated protein kinase kinase; PC, pancreatic cancer; PI3K, phosphatidylinositol-3 kinase; PLC, primary liver cancer; RCT, randomized controlled trial; VEGF, vascular endothelial growth factor.
\end{abstract}

\section{Introduction}

Members of a family of 3-hydroxy-3-methylglutaryl coenzyme A (HMG-CoA) reductase drugs, that inhibit the biosynthesis of cholesterol, are generally termed as statins (Murray et al. 1997; Gauthaman et al. 2009). Endo et al. (1976) started to study the effect of statins in humans more than 40 years ago. Their project was focused on searching for microbial metabolites that would inhibit HMG-CoA reductase and suppress de novo cholesterol biosynthesis followed by the reduction of plasma cholesterol levels in humans. They discovered a potent reductase inhibitor and named it mevastatin. Clinical trials with mevastatin were performed

Correspondence to: Eva Vidomanová, Biomedical Center Martin, Jessenius Faculty of Medicine in Martin, Comenius University in Bratislava, Mala Hora 11161/4D, 03601 Martin, Slovakia E-mail: evablahovcova@yahoo.com in the late 1970s in Japan, but this statin has never been used in standard clinical practice (Endo et al. 1976; Endo 1992, 2004; Jiang et al. 2014). The first commercially available statin was lovastatin, followed by fluvastatin, and pravastatin. All of them represent the first generation of natural products targeting HMG-CoA reductase (Alberts et al. 1980; Tobert et al 2003). A second generation statins are synthetic and more potent than those from the first generation. These include simvastatin, atorvastatin, cerivastatin, rosuvastatin and pitavastatin (Tobert et al. 2003).

The discovery of statins significantly changed the approach to dyslipidemic therapy and tremendously decreased morbidity and mortality from cardiovascular events. Statins had become a first choice in current clinical practice and pivotal in a primary and secondary prevention of cardiovascular disease (CVD) (Kubatka et al. 2014).

In addition to their original role to decrease serum cholesterol levels, more studies suggested that statins may inhibit 
carcinogenesis. They are beneficial for the treatment outcome of various types of cancer, while they may improve common cancer therapy strategies involving alkylating agents and antimetabolites (Han et al. 2011; Gopalan et al. 2013; Kim et al. 2014; Stoehr et al. 2014; Blahovcova et al. 2016; Likus et al. 2016; Liang et al. 2017).

\section{Biochemical properties of statins}

Among statins, cerivastatin, simvastatin, and lovastatin are most lipophilic, followed by mevastatin, fluvastatin, atorvastatin, rosuvastatin, and pravastatin (Likus et al. 2016). Pravastatin is extremely hydrophilic compared to the other statins. Its intermediate physiochemical properties and differences in hydrophilicity may have clinical significance with respect to factors such as cancer risk (Boudreau et al. 2010). Hydrophilic statin pravastatin is more hepatoselective than lipophilic statins cerivastatin, simvastatin, lovastatin, mevastatin, atorvastatin, rosuvastatin and fluvastatin, whereupon is pravastatin actively transported into the liver by members of the organic anion transporting polypeptide family (also known as OATPs). In contrast, lipophilic statins enter the liver by passive diffusion (Alfaqih et al. 2017). The sodium-independent organic anion transporter protein-1B1 (OATP1B1) is exclusively expressed in liver (Menter et al. 2011). However, studies on tissue samples revealed decreased levels of OATP1B1 in hepatocellular carcinoma tumor samples compared to normal liver (Cui et al. 2003; Zollner et al. 2005). Simvastatin inhibited the growth of most tumor cell lines more effectively than pravastatin in a dose-dependent manner. Poorly-differentiated cancer cells were generally more responsive to simvastatin than well-differentiated cancer cells, and the levels of HMG-CoA reductase expression did not consistently correlate with response to statin treatment. Hydrophilic drug pravastatin was ineffective in inhibiting the growth or altering the biologic behavior of selected tumor cell lines (Menter et al. 2011).

\section{The effect of statins on mevalonate pathway}

Statins decrease low-density lipoprotein (LDL) cholesterol levels by inhibiting HMG-CoA reductase enzyme. HMG$\mathrm{CoA}$ reductase catalyzes the conversion of $\mathrm{HMG}-\mathrm{CoA}$ into mevalonate and presents the rate-limiting step in hepatic cholesterol biosynthesis pathway (Figure 1) (Goldstein et al. 1990; Hindler et al. 2006). The product of HMG-CoA reductase activity, mevalonic acid, is a precursor of cholesterol and the isoprenoid intermediates farnesyl pyrophosphate (FPP) and geranylgeranyl pyrophosphate (GGPP). Both FPP and GGPP play a central role in the process of prenylation, where FPP or GGPP are post-translationally added to a protein to facilitate cell membrane anchoring (Ghavami et al. 2012, 2014; Likus et al. 2016). Isoprenoids are necessary for the post-translational modification of different proteins, such as GTPase proteins (Rho, Rac and Ras), which are important in many physiological processes. A large number of oncoproteins involved in a high percentage of human cancers, require post-translational isoprenylation for their activity and anchoring into the cell membrane (Sebti 2005). Therefore, the inhibition of non-steroidal isoprenoid molecules, such as FPP and GGPP production, and hence of oncoproteins prenylation, results in the decrease of their activity followed by decreasing of tumor cell proliferation, membrane integrity and cell signalling (Thurnher et al. 2012; Baenke et al. 2013; Pisanti et al. 2014). These processes also play crucial role in carcinogenesis and may explain the pleiotropic pharmacological properties of statins that are not based solely on cholesterol reduction (Campbell et al. 2006; Hindler et al. 2006; Osmak 2012; Kubatka et al. 2014).

\section{Cholesterol and cancer}

Cholesterol, the product of mevalonate pathway, can mask the cancer stem cell associated glycosphingolipid antigens and decreases their immunoreactivity (Novak et al. 2013; Kubatka et al. 2014). By contrast, some studies have reported that lower levels of LDL are associated with higher rates of cancer risk (Alsheikh-Ali et al. 2008). Several authors suggested that lower serum levels of total cholesterol are associated with higher oxidative DNA damage, which is thought to play a major role in carcinogenesis (Ames 1989; Kikuchi et al. 2013; Fujimoto et al. 2015). An inverse relationship between total serum cholesterol levels and increased risk of cancer is well known. There are several studies suggesting that an excessively low level of total cholesterol might be associated with an increased risk for cancer mortality (Hiatt et al. 1986; Knekt et al. 1988; Jacobs et al. 1992; Schuit et al. 1993; Eichholzer et al. 2000; Alsheikh et al. 2007; Kikuchi et al. 2013; Fujimoto et al. 2015). It is also possible that decreased level of total cholesterol could be due to cancer progression. Proliferating cancer cells display increased HMG-CoA reductase and LDL receptor activities, which can result in elevated cholesterol levels and higher cholesterol consumption comparing to healthy proliferating cells (Mollinedo 2015).

The relationship between serum cholesterol levels and the risk of cancer is an area of considerable research. In most of the clinical studies, low or reduced serum cholesterol levels were not associated with a higher incidence of cancer (Osmak 2012). Proteins involved in development of several malignant cancers can be associated with lipid rafts, cholesterol rich domains on plasma membrane and indicated a role for lipid rafts in tumor progression. Cholesterol, the key component of lipid rafts, can accumulate in malignant tissue, and therefore 


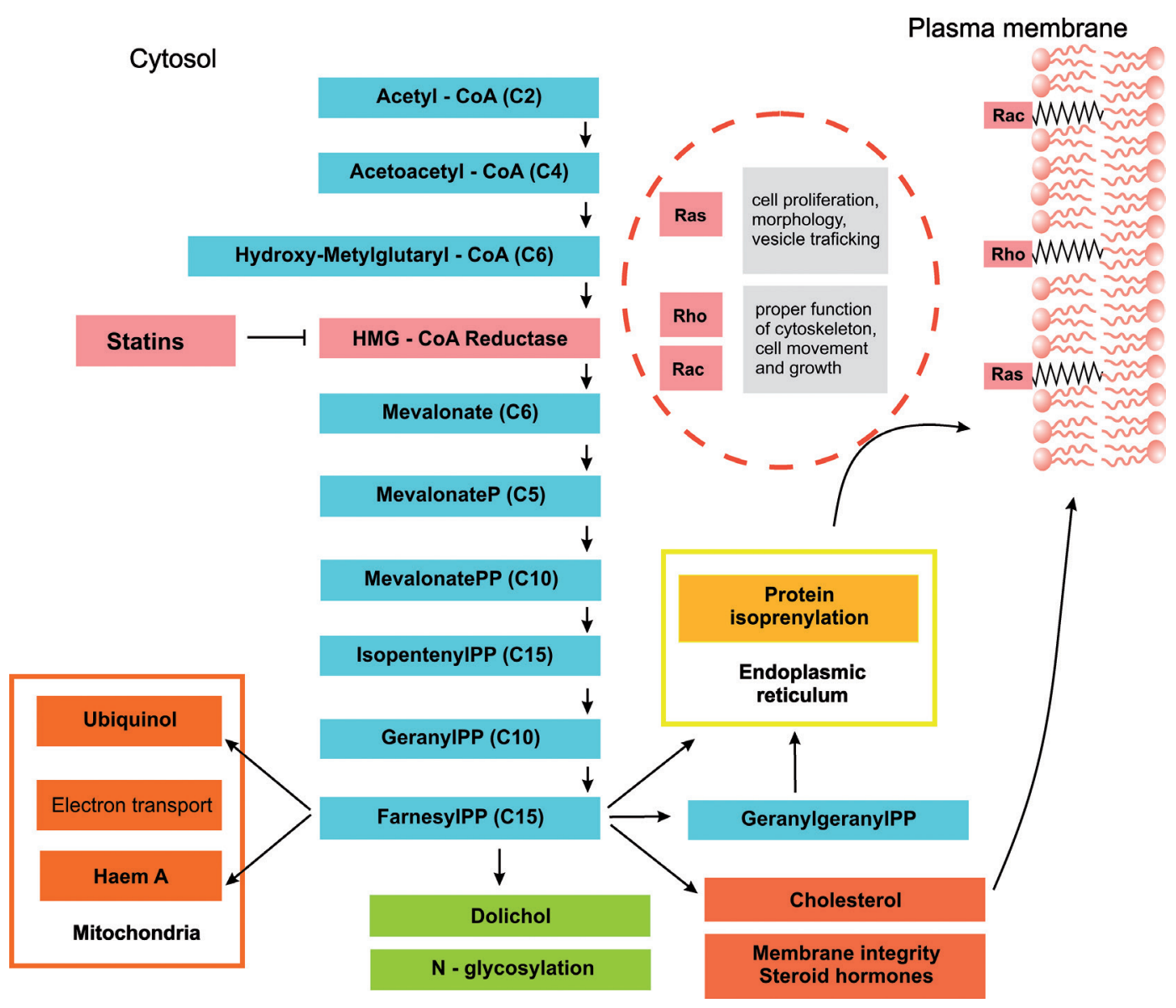

Figure 1. The schematic representation of mevalonate pathway and effect of statins. The mevalonate pathway performs several key products, which play an important role in many biological processes in eukaryotic cells. Cellular cholesterol and non-sterol isoprenoids are synthetized from acetyl-CoA in a multistep pathway. HMG-CoA reductase catalyzes the conversion of HMG-CoA into mevalonate and represents the rate-limiting step in the synthesis of cholesterol. The non-sterol isoprenoids, such as FPP, GGPP, ubiquinol and dolichol are produced exclusively through this pathway. Isoprenoid intermediates, such as farnesyl-PP and geranylgeranyl-PP, contain hydrophobic chains which are essential for the isoprenylation of proteins. The covalent attachment of the lipophilic isoprenyl groups enables prenylated proteins to be anchored into plasma membranes. This process is catalysed by prenyltransferases. Small GTP binging proteins, such as Ras, Rho and Rac, which are necessary in many physiological processes, represent the main group of polyprenylated proteins.

cholesterol content in tumor cells is subsequently higher than in normal cells (Mollinedo 2015). Moreover, the breast cancer and prostate cancer cell lines contained more lipid rafts and were more sensitive to cholesterol depletion-induced cell death that their normal counterparts. Results of the another study indicated that cancer cells contain increased levels of lipid rafts and suggested a potential use of raft modulating agents as anticancer drugs (Li et al. 2006).

\section{Effect of statins on cellular processes}

Experimental studies in vitro showed that statins exhibit antitumor effect against various cancer cells resulted in inhibition of cell proliferation, induction of apoptosis and inhibition of angiogenesis and metastasis (Osmak 2012; Mullen et al. 2016).

\section{Inhibition of proliferation}

Statins can negatively affect cell cycle, and therefore represent an important step in anticancer therapy (Gbelcová et al. 2017). Modulation of cell cycle regulatory proteins in cancer cells, particularly an upregulation of $p 21$ and $p 27$ expression and downregulation of cyclin-dependent kinase 2 activity (Ukomadu et al. 2003; Zhu et al. 2013), arrested them in the G1 or S phase, and occasionally in the G2/M phase (Jakóbi- 
siak et al. 1991; Crick et al. 1998; Zhu et al. 2013). Cells can fail to enter the $S$ phase when their level of cholesterol is depleted. Therefore, cells lacking cholesterol are arrested in either the G1 or G2 phase (Likus et al. 2016). Furthermore, dose- and time-dependent inhibition of renal cancer cells growth by cell cycle arrest and apoptosis induction is mediated through cholesterol deprivation and prenylation-associated mechanisms. This effect was abolished by substitution of mevalonate or GGPP (Woschek et al. 2016). Moreover, high sensitivity of cells to irradiation-induced cell death in G1 phase can be used in cancer radiotherapy (Chan et al. 2003; Alfaqih et al. 2017). These findings suggest that statins inhibit proliferation in cancer cells by various mechanisms, including reduction of prenylation and cholesterol depletion.

\section{Induction of apoptosis}

Ras activation promotes cell proliferation and survival through activation of the mitogen activated protein kinase kinase (MEK)/extracellular signal regulated kinase (ERK) and phosphatidylinositol-3 kinase (PI3K) pathways. Thus, inhibition of Ras activity is expected to inhibit Ras-dependent proliferation. Statins induce apoptosis in several cancer cell lines by enhancing Bim expression and by activation of caspase-3 (Tsubaki et al. 2017). The Ras/Raf/MEK/ERK signaling pathway plays the key role in the transmission of proliferative signals from membrane receptors and regulates the activity of many proteins involved in apoptosis. ERK phosphorylates transcription factors that influence the transcription Bcl-2 family of genes as well as other important genes involved in the regulation of apoptosis (Steelman et al. 2011). Lovastatin induce apoptosis in acute myelogenous leukemia (AML) cells by downregulation of the pro-survival Raf/MEK/ERK pathway. It is thought that lovastatin targets geranylgeranylated proteins that play an essential role in the constitutive activation of the Raf/MEK/ ERK pathway. In addition, the AML patient samples with high basal ERK1/2 activation appear to be more sensitive to lovastatin-induced apoptosis than those with lower basal ERK1/2 activation. This suggests that constitutive ERK1/2 activation appears to be a marker of lovastatin-sensitive tumor types. The abrogation of the ERK pathway is a key determinant of lovastatin efficacy and down-regulation of this pathway enables lovastatin to fully drive apoptosis by additional mechanisms of action (Wu et al. 2004; Steelman et al. 2011). In another study, statin-induced apoptosis in osteosarcoma cells was shown to be mediated by inhibition of extracellular-regulated kinase (ERK) signaling and downregulation of anti-apoptotic B-cell lymphoma protein 2 (Bcl-2) expression (Fromigue et al. 2006; Zhu et al. 2013). Other reports have suggested that statins mediate apoptotic response by activating Fas-induced apoptotic signaling via their ability to disrupt cholesterol enriched lipid rafts (Gniadecki et al. 2004; Zhu et al. 2013). However, simvastatin activates mitochondrial-mediated death pathway by inhibiting protein geranylgeranylation in HCT116 colorectal cancer cells (Zhu et al. 2013). Tamoxifen, a selective estrogen receptor modulator, is used in an adjuvant endocrine therapy for women with estrogen receptor positive breast cancer. The experiments in vitro and in vivo demonstrated that simvastatin combined with tamoxifen increased apoptosis in tamoxifen-resistant cancer cells and inhibited xenograft growth. Simvastatin may suppress tamoxifen-resistant cell growth by inhibiting minichromosome maintenance protein 7, retinoblastoma protein and subsequently inducing DNA damages (Liang et al. 2017). Statins can induce apoptosis through dysregulation of prenylation processes of signal molecules involved in ERK pathway.

\section{Impact on angiogenesis and metastasis}

The latest findings indicate that statins-induced decrease of Ras farnesylation is one of inhibiting processes in cancer development. For instance, cerivastatin inhibits both proliferation and invasion of aggressive breast cancer cell lines via inactivation of RhoA by decreased geranylgeranylation. This leads to RhoA relocation from cell membrane and deregulation of cell signaling required for cell proliferation and migration (Denoyelle et al. 2001). Also, the treatment with simvastatin significantly reduced membrane localization of RhoA. Furthermore, simvastatin exerts anti-inflammatory effects, induces angiogenesis and promotes endothelial cell growth (van Nieuw Amerongen et al. 2000). In effective cancer therapy is suggested that statins act most effectively together with chemotherapeutics. Recent studies reveal beneficial antineoplastic effects of statins mediated by alteration of apoptosis inhibitory effect of vascular endothelial growth factor (VEGF) and limited secretion of matrix metalloproteinases (Denoyelle et al. 2001; Likus et al. 2016). Wolfe et al. studied the effect of statins on breast cancer cells metastasis and observed an inhibition of metastasis (Wolfe et al. 2015). They identified transcriptional factor FOXO3a as a potential mediator of metastasis for using in in vitro and in vivo models. FOXO3a is a transcription factor, which has been described as a tumor suppressor in various tumors and triggers apoptosis. Further, they showed that statin therapy regulates protein FOXO3a activation, suggesting a potential mechanism for simvastatin's anti-metastatic effects (Wolfe et al. 2015). Downregulation of FOXO3a increases metastasis formation and predicts worse metastasis-free survival in patients with renal cell carcinoma ( $\mathrm{Ni}$ et al. 2014). These results suggest that statins can inhibit metastasis development and progression based on their ability to affect signal molecules involved in regulation of cell migration and cell proliferation. 


\section{Effect of statins in cell line studies}

Statins have highly variable biological outcomes (Gbelcová et al. 2017). The capacity of different statins for apoptosis induction was compared in different acute myelogenous leukemia cell lines. It was shown that cell lines were most sensitive to cerivastatin, ten-fold less sensitive to lovastatin and fluvastatin, and only weakly sensitive to atorvastatin (Wong et al. 2001; Kubatka et al. 2014). For instance, simvastatin, but not lovastatin, improved the survival rate in patients undergoing resection for early-stage pancreatic cancer (Wu et al. 2015). On the other hand, lovastatin was the only efficient statin in patients with colorectal cancer (Simon et al. 2012).

The anti-proliferative potential of lovastatin was evaluated in 59 different tumor cell lines. The sensitivity to lovastatin was highly dependent on the tumor lines assessed. Lovastatin induced a pronounced apoptotic response in cells derived from juvenile monomyelocitic leukemia, pediatric solid malignancies (medulloblastoma and rhabdomyosarcoma), choriocarcinoma, and squamous cell carcinomas of the cervix, head and neck juvenile monomyelocytic leukemia, medulloblastoma, that are sensitive to lovastatin-induced apoptosis (Dimitroulakos et al. 2001; Kubatka et al. 2014).

Importantly, the cytostatic and cytotoxic effects of statins are significantly more pronounced in malignant cells compared with non-malignant cells, which has been attributed to the higher expression of HMG-CoA reductase and a greater need for mevalonate-derived isoprenoids in cancer cells (Hentosh et al. 2001; Zhu et al. 2013). Results from in vitro studies suggest that the success of statin therapy depends on correctly selected combination of targeted cancer cells and statin drug.

\section{Effect of statins in animal and human studies}

Despite widespread and long-term use of statins, there is still a long-standing debate concerning their association with cancer. The connection between lipid-lowering therapy and cancer risk was observed with early animal studies, when all statins available in 1994 initiated or promoted cancer in rodents at concentrations equivalent to those commonly prescribed in humans. Lovastatin administration was associated with hepatocellular carcinomas and pulmonary adenomas, simvastatin with lung adenomas, liver and thyroid tumors, pravastatin-induced hepatocellular carcinomas and malignant lymphomas. Fluvastatin administration was associated with forestomach papilloma, and thyroid adenomas and carcinomas (Newman et al. 1996). Lovastatin administered in lower doses had not any carcinogenic effect on dogs, rats or monkeys (MacDonald et al. 1988). Moreover, pravastatin and simvastatin suppressed chemically-induced colon cancer in mice (Narisawa et al. 1994; Osmak 2012). On the contrary, the large randomized controlled trials (RCTs), focused on detection increased cancer incidence and cancer mortality after statins administration, were first to suggest that statins can prevent cancer (Demierre et al. 2005). Number of clinical trials and epidemiologic studies have been investigated the association between statin use and cancer risk, but the results are often inconclusive and debatable (Fujimoto et al. 2015).

Nevertheless, an increasing amount of data supports an inverse relation between statins use and cancer risk. The findings for prostate cancer are the most promising of all cancers studied. Administration of these drugs seems to be also associated with improved prostate cancer specific survival, particularly in men undergoing radiotherapy, suggesting usefulness of statins in secondary and tertiary prevention. The epidemiological evidence is supported by preclinical studies showing that statins directly inhibit prostate cancer development and progression in cell-based and animal-based models. Currently, there are no sufficient data to support the use of statins for the primary prevention of prostate cancer and further research is needed (Alfaqih et al. 2017).

Concerning the pancreatic cancer (PC), even though not all of the published data are convincing (Bonovas et al. 2008; Bradley et al. 2010; Chiu et al. 2011; Cui et al. 2012), in several studies statins have been proven to significantly decrease the PC risk (Khurana et al. 2007; Nielsen et al. 2012; Walker et al. 2015; Chen et al. 2016). Lee et al. (2016) have shown that statin application was associated with a lower risk of cancer mortality, especially among simvastatin and atorvastatin users. They found that the use of simvastatin and atorvastatin after cancer diagnosis is associated with longer survival in patients with non-metastatic pancreatic adenocarcinoma. Walker et al. (2015) observed associations in men only, and PC risk was inversely related to the duration of statin use. Interestingly, results from meta-analyses of randomized controlled trial data show that statins may reduce the risk of acute pancreatitis and increase diabetes risk (Desai et al. 2014), and these conditions are associated with increased PC risk (Walker et al. 2015). Simvastatin increased survival of pancreatic cancer patients more potently than the other statins (Jeon et al. 2015). The most frequently mutated gene in pancreatic ductal adenocarcinoma KRAS drives cancer development and growth (Bryant et al. 2014), and may be one of the factors in lowering PC risk by statin use. Conversely, Fujimoto et al. suggested that statin administration is associated with an increased risk for colorectal and PC. These authors did not find any association of lung, gastric and prostate cancer with statins (Fujimoto et al. 2015). Significantly increased risk of cancer was found predominantly for high potency statins, such as atorvastatin, rosuvastatin and pitavastatin. However, inverse associations between statin use and cancer risk were found for breast cancer and hematological malignancies (Fujimoto et al. 2015). 
Some studies reported that statins were associated with a decreased risk of breast cancer (Cauley et al. 2006; Brewer et al. 2013; Sendur et al. 2014; Fujimoto et al. 2015). Ahern et al. (2014) suggested that statins, particularly simvastatin, may reduce the risk of breast cancer recurrence. Murakami et al. (2016) demonstrated that lovastatin is a potential chemopreventive agent against breast cancer. Atorvastatin exhibited only a protective tendency against breast cancer. Moreover, breast cancer patients who use statins or specifically, lipophilic statins showed improved recurrence-free survival. Statin users also had improved overall survival and cancer-specific survival (Ahern et al. 2011; Manthravadi et al. 2016). Mansourian et al. (2016) in their meta-analysis suggested that statin use results in $21 \%$ reduction in breast cancer recurrence and $16 \%$ reduction in mortality rate. These data provide a justification for launching further randomized clinical trials. However, they were unable to differentiate between various statins in terms of effectiveness and duration of use. Despite the promising preclinical results, no randomized control trials have evaluated the effects of statins on reduction of breast cancer risk. Report of Mansourian and coauthors is consistent with previously reported data, which demonstrated a lower recurrence rates in patients whose tumors expressed HMG-CoA reductase (Borgquist et al. 2008; Manthravadi et al. 2016). Furthermore, this benefit was confined to patients who used lipophilic statins and did not extend to users of hydrophilic statins. This strengthens the hypothesis derived from preclinical studies that the anti-cancer effect of statins may be independent of its cholesterol lowering effect and mediated by modulation of cell signaling (Ahern et al. 2014; Manthravadi et al. 2016). There is also a paucity of data pertaining to the role of statins across a spectrum of breast cancer molecular subtypes. In this regard, the results from different studies have been inconsistent. While some studies hint at a role of estrogen receptor status as a predictive biomarker for statin efficacy (Botteri et al. 2013; Ahern et al. 2014), others have found no such association (Desai et al. 2015; Manthravadi et al. 2016).

Gray et al. (2016) suggest that statin use appears to be associated with reduced mortality in colorectal cancer. However, the magnitude of the effect is weak and the association may not be causal. This is consistent with findings from study of Jung et al. (2016), which observed that statin use seemed to be associated with a reduced risk of advanced adenoma, whereas it did not significantly reduce the risk of any adenoma. Statins may have a role in colorectal cancer chemoprevention by acting at the later stages of progression rather than at the early stages of adenoma initiation and development in the adenoma-carcinoma sequence (Jung et al. 2016). A protective effect of statins on primary liver cancer (PLC) was observed, most notably of rosuvastatin (Zhong et al. 2016). This protective effect is more pronounced in high-risk populations, is dose-dependent, and persisted in patients with diabetes, hepatitis $\mathrm{B}$ or $\mathrm{C}$ virus infection. These findings support the suggestion that statins can serve as chemopreventive agents of PLC and reduce the public health burden of this malignancy. Prospective cohort studies with sufficient follow-up duration and large sample size are warranted to address this issue before formally recommending statins in preventing PLC (Zhong et al. 2016). Liu et al. have shown that lovastatin and fluvastatin did not significantly reduce the lung cancer risk in patients with chronic obstructive pulmonary disease (COPD) (Liu et al. 2016). However, rosuvastatin, atorvastatin, simvastatin and pravastatin showed strong dose-dependent chemopreventive effect against lung cancer risk in patients with COPD (Liu et al. 2016). Some experimental studies have suggested that statins have preventive potential against hematopoietic malignancies (Matar et al. 1999; Xia et al. 2001; Gronich et al. 2004; Vinogradova et al. 2011; Fujimoto et al. 2015). On the other hand, there is still number of epidemiological studies and clinical trials assessing the statins for cancer treatment that have drawn controversial conclusions (Strandberg et al. 2004; Emberson et al. 2012; Zhu et al. 2013). Significant associations with increased risks of cancers were predominantly found for high potency statins such as atorvastatin, rosuvastatin, and pitavastatin (Fujimoto et al. 2015). Hung et al. (2015) demonstrated an association between statin use and thyroid cancer. Studies in vivo and clinical trials indicate that statins are beneficial in therapy of some types of cancer, but only as an adjuvant therapy with thoroughly considered risk factors. The lack of conformity among clinical trials and observational epidemiologic studies of statins in the prevention of human cancers may be caused by the fact that the most of them have been observational and retrospective. Moreover, many prospective clinical trials evaluated cancer as secondary endpoint and limiting the evaluation of statins for cancer prevention (Osmak 2012).

\section{Conclusion}

Statins have several effects on human health. Besides the decrease of the lipidic levels activity, statins can be used for cancer treatment due to inhibition of mevalonate pathway. By controlling the mevalonate synthesis, it is possible to alter cholesterol synthesis and prenylation patterns and thereby affecting the function of proteins and oncoproteins. Due to diverse roles of the proteins and differences between cell types and tissues, the therapeutic effects of statins based on inhibition of the mevalonate pathway are varying. The use of the mevalonate pathway as therapeutic target is difficult, because a large number of cellular processes are influenced. Recent data revealed the molecular mechanisms involved in statin-induced cancer cell death and lay the foundation 
to explore the role of statins as an adjuvant in combination therapies for cancer treatment. The epidemiological evidence suggests the positive effect of statin treatment of prostate, pancreas, breast and colorectal cancer, and chemopreventive effect against hematopoietic malignancies and lung cancer risk in patients with COPD. These types of cancer are candidate for statin use as adjuvant therapy. In addition, statins could offer a novel approach in the therapy of aggressive forms of cancer in combination with other anticancer treatments. Association between statin use and cancer is complex, organ-dependent and confounded by intermediary health condition. Therefore, carefully designed studies are required for better understanding of statin molecular effect and therapeutic use.

Acknowledgements. The authors are very thankful to Miroslav Škoviera for figure preparation. We thank Terézia Okajčeková for technical assistance. This work was supported by the Slovak Research and Development Agency under the contract APVV15-0217 and VEGA 1/0178/17. This publication is the result of the project implementation "CENTER OF TRANSLATIONAL MEDICINE”, ITMS code 26220220021 supported by the Operational Programme Research and Innovation funded by the ERDF.

Conflict of interest. The authors declare no conflict of interests.

\section{References}

Ahern T. P., Pedersen L., Tarp M., Cronin-Fenton D. P., Garne J. P., Silliman R. A., Sørensen H. T., Lash T. L. (2011): Statin prescriptions and breast cancer recurrence risk: a Danish nationwide prospective cohort study. J. Natl. Cancer Inst. 103, 1461-1468 https://doi.org/10.1093/jnci/djr291

Ahern T. P., Lash T. L., Damkier P., Christiansen P. M., CroninFenton D. P. (2014): Statins and breast cancer prognosis: evidence and opportunities. The Lancet Oncology 15, 461-468 https://doi.org/10.1016/S1470-2045(14)70119-6

Alberts A. W., Chen J., Kuron G., Hunt V., Huff J., Hoffman C., Rothrock J., Lopez M., Joshua H., Harris E. et al. (1980): Mevinolin: a highly potent competitive inhibitor of hydroxymethylglutarylcoenzyme A reductase and a cholesterol-lowering agent. Proc. Natl. Acad. Sci. USA 77, 3957-3961 https://doi.org/10.1073/pnas.77.7.3957

Alfaqih M. A., Allott E. H., Hamilton R. J., Freeman M. R., Freedland S. J. (2017): The current evidence on statin use and prostate cancer prevention: are we there yet? Nat. Rev. Urol. 14, 107-119 https://doi.org/10.1038/nrurol.2016.199

Alsheikh-Ali A. A., Maddukuri P. V., Han H., Karas R. H. (2007): Effect of the magnitude of lipid lowering on risk of elevated liver enzymes, rhabdomyolysis, and cancer: insights from large randomized statin trials. J. Am. Coll. Cardiol. 50, 409-418 https://doi.org/10.1016/j.jacc.2007.02.073

Alsheikh-Ali A. A., Trikalinos T. A., Kent D. M., Karas R. H. (2008): Statins, low-density lipoprotein cholesterol, and risk of cancer. J. Am. Coll. Cardiol. 52, 1141-1147 https://doi.org/10.1016/j.jacc.2008.06.037

Ames B. N. (1989): Endogenous DNA damage as related to cancer and aging. Mutat. Res. 214, 41-46

https://doi.org/10.1016/0027-5107(89)90196-6

Baenke F., Peck B., Miess H., Schulze A. (2013): Hooked on fat: the role of lipid syn-thesis in cancer metabolism and tumour development. Dis. Model Mech. 6, 1353-1363 https://doi.org/10.1242/dmm.011338

Blahovcova E., Skovierova H., Strnadel J. Mistuna D., Halasova E. (2016): Apoptosis in cancer cells. In: Information Technologies in Medicine (Eds. E. Pietka, P. Badura, J. Kawa and W. Wieclawek), pp. 207-213, Springer-Verlag Berlin https://doi.org/10.1007/978-3-319-39904-1_18

Bonovas S., Filioussi K., Sitaras N. M. (2008): Statins are not associated with a reduced risk of pancreatic cancer at the population level, when taken at low doses for managing hypercholesterolemia: evidence from a meta-analysis of 12 studies. Am. J. Gastroenterol. 103, 2646-2651 https://doi.org/10.1111/j.1572-0241.2008.02051.x

Borgquist S., Jögi A., Pontén F., Rydén L., Brennan D. J., Jirström K. (2008): Prognostic impact of tumour-specific HMG-CoA reductase expression in primary breast cancer. Breast Cancer Res. 10, R79 https://doi.org/10.1186/bcr2146

Botteri E., Munzone E., Rotmensz N., Cipolla C., De Giorgi V., Santillo B., Zanelotti A., Adamoli L., Colleoni M., Viale G. et al. (2013): Therapeutic effect of beta-blockers in triple-negative breast cancer postmenopausal women. Breast Cancer Res. Treat. 140, 567-575 https://doi.org/10.1007/s10549-013-2654-3

Boudreau D. M., Yu O., Johnson J. (2010): Statin use and cancer risk: a comprehensive review. Expert Opin. Drug. Saf. 9, 603-621 https://doi.org/10.1517/14740331003662620

Bradley M. C., Hughes C. M., Cantwell M. M., Murray L. J. (2010): Statins and pancreatic cancer risk: a nested case-control study. Cancer Causes Control 21, 2093-2100 https://doi.org/10.1007/s10552-010-9628-0

Brewer T. M., Masuda H., Liu D. D., Iwamoto T., Kai K., Barnett C. M., Woodward W. A., Reuben J. M., Yang P., Hortobagyi G. N., Ueno N. T. (2013): Statin use in primary inflammatory breast cancer: a cohort study. Br. J. Cancer 109, 318-324 https://doi.org/10.1038/bjc.2013.342

Bryant K. L., Mancias J. D., Kimmelman A. C., Der C. J. (2014): KRAS: feeding pancreatic cancer proliferation. Trends. Biochem. Sci. 39, 91-100 https://doi.org/10.1016/j.tibs.2013.12.004

Campbell M. J., Esserman L. J., Zhou Y., Shoemaker M., Lobo M., Borman E., Baehner F., Kumar A. S., Adduci K., Marx C. et al. (2006): Breast cancer growth prevention by statins. Cancer Res. 66, 8707-8714 https://doi.org/10.1158/0008-5472.CAN-05-4061

Cauley J. A., McTiernan A., Rodabough R. J., LaCroix A., Bauer D. C., Margolis K. L., Paskett E. D., Vitolins M. Z., Furberg C. D., Chlebowski R. T., Women's Health Initiative Research Group (2006): Statin use and breast cancer: prospective results from the Women's Health Initiative. J. Natl. Cancer Inst. 98, 700-707 https://doi.org/10.1093/jnci/djj188 
Chan K. K., Oza A. M., Siu L. L. (2003): The statins as anticancer agents. Clin. Cancer Res. 9, 10-19

Chen M. J., Tsan Y. T., Liou J. M., Lee Y. C., Wu M. S., Chiu H. M., Wang H. P., Chen P. C. (2016): Statins and the risk of pancreatic cancer in Type 2 diabetic patients--A population-based cohort study. Int. J. Cancer 138, 594-603 https://doi.org/10.1002/ijc.29813

Chiu H. F., Chang C. C., Ho S. C., Wu T. N., Yang C. Y. (2011): Statin use and the risk of pancreatic cancer: a population-based case-control study. Pancreas 40, 669-672 https://doi.org/10.1097/MPA.0b013e31821fd5cd

Crick D. C., Andres D. A., Danesi R., Macchia M., Waechter C. J. (1998): Geranylgeraniol overcomes the block of cell proliferation by lovastatin in C6 glioma cells. J. Neurochem. 70, 2397-2405 https://doi.org/10.1046/j.1471-4159.1998.70062397.x

Cui X., Xie Y., Chen M., Li J., Liao X., Shen J., Shi M., Li W., Zheng H., Jiang B. (2012): Statin use and risk of pancreatic cancer: a meta-analysis. Cancer Causes Control 23, 1099-1111 https://doi.org/10.1007/s10552-012-9979-9

Cui Y., Konig J., Nies A. T., Pfannschmidt M., Hergt M., Franke W. W., Alt W., Moll R., Keppler D. (2003): Detection of the human organic anion transporters SLC21A6 (OATP2) and SLC21A8 (OATP8) in liver and hepatocellular carcinoma. Lab. Invest. 83, 527-538 https://doi.org/10.1097/01.LAB.0000065015.02412.48

Demierre M. F., Higgins P. D., Gruber S. B., Hawk E., Lippman S. M. (2005): Statins and cancer prevention. Nat. Rev. Cancer 5, 930-942 https://doi.org/10.1038/nrc1751

Denoyelle C., Vasse M., Korner M., Mishal Z., Ganne F., Vannier J. P., Soria J., Soria C. (2001): Cerivastatin, an inhibitor of HMGCoA reductase, inhibits the signaling pathways involved in the invasiveness and metastatic properties of highly invasive breast cancer cell lines: an in vitro study. Carcinogenesis 22, $1139-1148$ https://doi.org/10.1093/carcin/22.8.1139

Desai C. S., Martin S. S., Blumenthal R. S. (2014): Non-cardiovascular effects associated with statins. BMJ Clin. Res. 349, g3743 https://doi.org/10.1136/bmj.g3743

Desai P., Lehman A., Chlebowski R. T., Kwan M. L., Arun M., Manson J. E., Lavasani S., Wasswertheil-Smoller S., Sarto G. E., LeBoff M. et al. (2015): Statins and breast cancer stage and mortality in the Women's Health Initiative. Cancer Causes Control 26, 529-539 https://doi.org/10.1007/s10552-015-0530-7

Dimitroulakos J., Ye L. Y., Benzaquen M., Moore M. J., Kamel-Reid S., Freedman M. H., Yeger H., Penn L. Z. (2001): Differential sensitivity of various pediatric cancers and squamous cell carcinomas to lovastatin-induced apoptosis: therapeutic implications. Clin. Cancer Res. 7, 158-167

Eichholzer M., Stahelin H. B., Gutzwiller F., Lüdin E., Bernasconi F. (2000): Association of low plasma cholesterol with mortality for cancer at various sites in men: 17-y follow-up of the prospective Basel study. Am. J. Clin. Nutr. 71, 569-574

Emberson J. R., Kearney P. M., Blackwell L., Newman C., Reith C., Bhala N., Holland L., Peto R., Keech A. et al. (2012): Lack of effect of lowering LDL cholesterol on cancer: meta-analysis of individual data from 175,000 people in 27 randomised trials of statin therapy. PloS One 7, e2984

Endo A. (1992): The discovery and development of HMG-CoA reductase inhibitors Atheroscler. Suppl. 33, 1569-1582

Endo A. (2004): The origin of the statins. Atheroscler. Suppl. 5, $125-130$ https://doi.org/10.1016/j.atherosclerosissup.2004.08.033

Endo A., Kuroda M., Tsujita Y. (1976): ML-236A, ML-236B, and ML-236C, new inhibitors of cholesterogenesis produced by Penicillium citrinium. J. Antibiot. (Tokyo) 29, 1346-1348 https://doi.org/10.7164/antibiotics.29.1346

Fromigue O., Haÿ E., Modrowski D., Bouvet S., Jacquel A., Auberger P., Marie P. J. (2006): RhoA GTPase inactivation by statins induces osteosarcoma cell apoptosis by inhibiting $\mathrm{p} 42 /$ p44-MAPKs-Bcl-2 signaling independently of BMP-2 and cell differentiation. Cell Death Differ. 13, 1845-1856 https://doi.org/10.1038/sj.cdd.4401873

Fujimoto M., Higuchi T., Hosomi K., Takada M. (2015): Association between statin use and cancer: data mining of a spontaneous reporting database and a claims database. Int. J. Med. Sci. 12, 223-233 https://doi.org/10.7150/ijms.10656

Gauthaman K., Fong C. Y., Bongso A. (2009): Statins, stem cells, and cancer. J. Cell Biochem. 106, 975-983 https://doi.org/10.1002/jcb.22092

Gbelcová H., Rimpelová S., Ruml T., Fenclová M., Kosek V., Hajšlová J., Strnad H., Kolář M., Vítek L. (2017): Variability in statin-induced changes in gene expression profiles of pancreatic cancer. Sci. Rep. 7, 44219

https://doi.org/10.1038/srep44219

Ghavami S., Yeganeh B., Stelmack G. L., Kashani H. H., Sharma P., Cunnington R., Rattan S., Bathe K., Klonisch T., Dixon I. M. et al. (2012): Apoptosis, autophagy and ER stress in mevalonate cascade inhibition-induced cell death of human atrial fibroblasts. Cell Death Dis. 3, e330 https://doi.org/10.1038/cddis.2012.61

Ghavami S., Sharma P., Yeganeh B., Ojo O. O., Jha A., Mutawe M. M., Kashani H. H., Los M. J., Klonisch T., Unruh H., Halayko A. J. (2014): Airway mesenchymal cell death by mevalonate cascade inhibition: integration of autophagy, unfolded protein response and apoptosis focusing on Bcl2 family proteins. Biochim. Biophys. Acta 1843, 1259-1271 https://doi.org/10.1016/j.bbamcr.2014.03.006

Gniadecki R. (2004): Depletion of membrane cholesterol causes ligand-independent activation of Fas and apoptosis. Biochem. Biophys. Res. Commun. 320, 165-169 https://doi.org/10.1016/j.bbrc.2004.05.145

Goldstein J. L., Brown M. S. (1990): Regulation of the mevalonate pathway. Nature 343, 425-430 https://doi.org/10.1038/343425a0

Gopalan A., Yu W., Sanders B. G., Kline K. (2013): Simvastatin inhibition of mevalonate pathway induces apoptosis in human breast cancer cells via activation of JNK/CHOP/DR5 signaling pathway. Cancer Lett. 329, 9-16 https://doi.org/10.1016/j.canlet.2012.08.031

Gray R. T., Coleman H. G., Hughes C., Murray L. J., Cardwell C. R. (2016): Statin use and survival in colorectal cancer: Results from a population-based cohort study and an updated systematic review and meta-analysis. Cancer Epidemiol. 45, 71-81 
https://doi.org/10.1016/j.canep.2016.10.004

Gronich N., Drucker L., Shapiro H., Radnay J., Yarkoni S., Lishner M. (2004): Simvastatin induces death of multiple myeloma cell lines. J. Investig. Med. 52, 335-344 https://doi.org/10.1136/jim-52-05-34

Han J. Y., Lim K. Y., Yu S. Y., Yun T., Kim H. T., Lee J. S. (2011): A phase 2 study of irinotecan, cisplatin, and simvastatin for untreated extensive-disease small cell lung cancer. Cancer 117, 2178-2185 https://doi.org/10.1002/cncr.25790

Hentosh P., Yuh S. H., Elson C. E., Peffley D. M. (2001): Sterolindependent regulation of 3-hydroxy-3-methylglutaryl coenzyme A reductase in tumor cells. Mol. Carcinogen. 32, 154-166 https://doi.org/10.1002/mc.1074

Hiatt R. A., Fireman B. H. (1986): Serum cholesterol and the incidence of cancer in a large cohort. J. Chronic Dis. 39, 861-870 https://doi.org/10.1016/0021-9681(86)90034-2

Hindler K., Cleeland C. S., Rivera E., Collard C. D. (2006): The role of statins in cancer therapy. Oncologist 11, 306-315 https://doi.org/10.1634/theoncologist.11-3-306

Hung S. H., Lin H. C., Chung S. D. (2015): Statin use and thyroid cancer: a population-based case-control study. Clin. Endocrinol. (Oxf) 83, 111-116 https://doi.org/10.1111/cen.12570

Jacobs D., Blackburn H., Higgins M., Reed D., Iso H., McMillan G., Neaton J., Nelson J., Potter J., Rifkind B. (1992): Report of the Conference on Low Blood Cholesterol: Mortality Associations. Circulation 86, 1046-1060 https://doi.org/10.1161/01.CIR.86.3.1046

Jakóbisiak M., Bruno S., Skierski J. S., Darzynkiewicz Z. (1991): Cell cycle-specific effects of lovastatin. Proc. Natl. Acad. Sci. USA 88, 3628-3632 https://doi.org/10.1073/pnas.88.9.3628

Jaswal R. S., Kaushal R. K., Goel A., Pathania K. (2003): Role of $\mathrm{C}$-reactive protein in deciding duration of antibiotic therapy in neonatal septicemia. Indian Pediatr. 40, 880-883

Jeon C. Y., Pandol S. J., Wu B., Cook-Wiens G., Gottlieb R. A., Merz C. N., Goodman M. T. (2015): The Association of statin use after cancer diagnosis with survival in pancreatic cancer patients: A SEER-Medicare analysis. PLoS One 10, e0121783 https://doi.org/10.1371/journal.pone.0121783

Jiang P., Mukthavaram R., Chao Y., Nomura N., Bharati I. S., Fogal V., Pastorino S., Teng D., Cong X., Pingle S. C. et al. (2014): In vitro and in vivo anticancer effects of mevalonate pathway modulation on human cancer cells. Br. J. Cancer 111, 1562-1571 https://doi.org/10.1038/bjc.2014.431

Jung Y. S., Park C. H., Eun C. S., Park D. I., Han D. S. (2016): Statin use and the risk of colorectal adenoma: A meta-analysis. J. Gastroenterol. Hepatol. 31, 1823-1830 https://doi.org/10.1111/jgh.13393

Khurana V., Sheth A., Caldito G., Barkin J. S. (2007): Statins reduce the risk of pancreatic cancer in humans: a case-control study of half a million veterans. Pancreas 34, 260-265 https://doi.org/10.1097/MPA.0b013e318030e963

Kikuchi H., Nanri A., Hori A., Sato M., Kawai K., Kasai H., Mizoue T. (2013): Lower serum levels of total cholesterol are associated with higher urinary levels of 8-hydroxydeoxyguanosine. Nutr. Metab. 10, 59 https://doi.org/10.1186/1743-7075-10-59

Kim S. T., Kang J. H., Lee J., Park S. H., Park J. O., Park Y. S., Lim H. Y., Hwang I. G., Lee S. C., Park K. W. et al. (2014): Simvastatin plus capecitabine-cisplatin versus placebo plus capecitabinecisplatin in patients with previously untreated advanced gastric cancer: a double-blind randomised phase 3 study. Eur. J. Cancer 50, 2822-2830 https://doi.org/10.1016/j.ejca.2014.08.005

Knekt P., Reunanen A., Aromaa A., Heliövaara M., Hakulinen T., Hakama M. (1988): Serum cholesterol and risk of cancer in a cohort of 39,000 men and women. J. Clin. Epidemiol. 41, 519-530 https://doi.org/10.1016/0895-4356(88)90056-X

Kubatka P., Kruzliak P., Rotrekl V., Jelinkova S., Mladosievicova B. (2014): Statins in oncological research: from experimental studies to clinical practice. Crit. Rev. Oncol. Hematol. 92, 296-311 https://doi.org/10.1016/j.critrevonc.2014.08.002

Lee H. S., Lee S. H., Lee H. J., Chung M. J., Park J. Y., Park S. W., Song S. Y., Bang S. (2016): Statin use and its impact on survival in pancreatic cancer patients. Medicine (Baltimore) 95, e3607 https://doi.org/10.1097/MD.0000000000003607

Li Y. C., Park M. J., Ye S.K., Kim C. W., Kim Y.N. (2006): Elevated levels of cholesterol-rich lipid rafts in cancer cells are correlated with apoptosis sensitivity induced by cholesterol-depleting agents. Am. J. Pathol. 168, 1107-1118 https://doi.org/10.2353/ajpath.2006.050959

Liang Z., Li W., Liu J., Li J., He F., Jiang Y., Yang L., Li P., Wang B., Wang Y. et al. (2017): Simvastatin suppresses the DNA replication licensing factor MCM7 and inhibits the growth of tamoxifen-resistant breast cancer cells. Sci. Rep. 7, 41776 https://doi.org/10.1038/srep41776

Likus W., Siemianowicz K., Bieńk K., Pakuła M., Pathak H., Dutta C., Wang Q., Shojaei S., Assaraf Y. G., Ghavami S. et al. (2016): Could drugs inhibiting the mevalonate pathway also target cancer stem cells? Drug Resist. Updat. 25, 13-25 https://doi.org/10.1016/j.drup.2016.02.001

Liu J. C., Yang T. Y., Hsu Y. P., Hao W. R., Kao P. F., Sung L. C., Chen C. C., Wu S. Y. (2016): Statins dose-dependently exert a chemopreventive effect against lung cancer in COPD patients: a population-based cohort study. Oncotarget 7, 59618-59629

https://doi.org/10.18632/oncotarget.11162

MacDonald J. S., Gerson R. J., Kornbrust D. J., Kloss M. W., Prahalada S., Berry P. H., Alberts A. W., Bokelman D. L. (1988): Preclinical evaluation of lovastatin. Am. J. Cardiol. 62, 16-27 https://doi.org/10.1016/0002-9149(88)90003-3

Mansourian M., Haghjooy-Javanmard S., Eshraghi A., Vaseghi G., Hayatshahi A., Thomas J. (2016): Statins use and risk of breast cancer recurrence and death: a systematic review and meta-analysis of observational studies. J. Pharm. Pharm. Sci. 19, 72-81 https://doi.org/10.18433/J3202B

Manthravadi S., Shrestha A., Madhusudhana S. (2016): Impact of statin use on cancer recurrence and mortality in breast cancer: A systematic review and meta-analysis. Int. J. Cancer 139, 1281-1288 https://doi.org/10.1002/ijc.30185

Matar P., Rozados V. R., Binda M. M., Roggero E. A., Bonfil R. D., Scharovsky O. G. (1999): Inhibitory effect of Lovastatin on 
spontaneous metastases derived from a rat lymphoma. Clin. Exp. Metastasis 17, 19-25 https://doi.org/10.1023/A:1026448026716

Menter D. G., Ramsauer V. P., Harirforoosh S., Chakraborty K., Yang P., Hsi L., Newman R. A., Krishnan K. (2011): Differential effects of pravastatin and simvastatin on the growth of tumor cells from different organ sites. PLoS One 6, e28813 https://doi.org/10.1371/journal.pone.0028813

Mollinedo F., Gajate C. (2015): Lipid rafts as major platforms for signaling regulation in cancer. Adv. Biol. Regul. 57, 130-146 https://doi.org/10.1016/j.jbior.2014.10.003

Mullen P. J., Yu R., Longo J., Archer M. C., Penn L. Z. (2016): The interplay between cell signalling and the mevalonate pathway in cancer. Nat. Rev. Cancer. 16, 718-731

https://doi.org/10.1038/nrc.2016.76

Murakami R., Chen C., Lyu S. Y., Lin C. E., Tzeng P. C., Wang T. F., Chang J. C., Shieh Y. H., Chen I. F., Huang S. K., Lin H. W. (2016): Lovastatin lowers the risk of breast cancer: a populationbased study using logistic regression with a random effects model. Springerplus 5, 1932 https://doi.org/10.1186/s40064-016-3606-2

Murray C. J. L., Lopez A. D. (1997): Mortality by cause for eight regions of the world: Global burden of disease study. Lancet 349, 1269-1276 https://doi.org/10.1016/S0140-6736(96)07493-4

Narisawa T., Fukaura Y., Terada K., Umezawa A., Tanida N., Yazawa K., Ishikawa C. (1994): Prevention of 1,2-dimethylhydrazine-induced colon tumorigenesis by HMG-CoA reductase inhibitors, pravastatin and simvastatin, in ICR mice. Carcinogenesis 15, 2045-2048 https://doi.org/10.1093/carcin/15.9.2045

Newman T. B., Hulley S. B. (1996): Carcinogenicity of lipidlowering drugs. JAMA 275, 55-60 https://doi.org/10.1001/jama.1996.03530250059028

Ni D., Ma X., Li H. Z., Gao Y., Li X. T., Zhang Y., Ai Q., Zhang P., Song E. L., Huang Q. B., Fan Y., Zhang X. (2014): Downregulation of FOXO3a promotes tumor metastasis and is associated with metastasis-free survival of patients with clear cell renal cell carcinoma. Clin. Cancer Res. 20, 1779-1790 https://doi.org/10.1158/1078-0432.CCR-13-1687

Nielsen S. F., Nordestgaard B. G., Bojesen S. E. (2012): Statin use and reduced cancer-related mortality. N. Engl. J. Med. 367, 1792-1802 https://doi.org/10.1056/NEJMoa1201735

Novak A., Binnington B., Ngan B., Chadwick K., Fleshner N., Lingwood C. A. (2013): Cholesterol masks membrane glycosphingolipid tumor-associated antigens to reduce their immunodetection in human cancer biopsies. Glycobiology 23, $1230-1239$ https://doi.org/10.1093/glycob/cwt059

Osmak M. (2012): Statins and cancer: current and future prospects. Cancer Lett. 324, 1-12 https://doi.org/10.1016/j.canlet.2012.04.011

Pisanti S., Picardi P., Ciaglia E., D'Alessandro A., Bifulco M. (2014): Novel prospects of statins as therapeutic agents in cancer. Pharmacol. Res. 88, 84-98 https://doi.org/10.1016/j.phrs.2014.06.013

Schuit A. J., Van Dijk C. E., Dekker J. M., Schouten E. G., Kok F. J. (1993): Inverse association between serum total cholesterol and cancer mortality in Dutch civil servants. Am. J. Epidemiol. 137, 966-976 https://doi.org/10.1093/oxfordjournals.aje.a116769

Sebti S. M. (2005): Protein farnesylation: implications for normal physiology, malignant transformation, and cancer therapy. Cancer Cell 7, 297-300 https://doi.org/10.1016/j.ccr.2005.04.005

Sendur M. A., Aksoy S., Yazici O. Ozdemir N. Y., Zengin N., Altundag K. (2014): Statin use may improve clinicopathological characteristics and recurrence risk of invasive breast cancer. Med. Oncol. 31, 835 https://doi.org/10.1007/s12032-013-0835-X

Simon M. S., Rosenberg C. A., Rodabough R. J., Greenland P., Ockene I., Roy H. K., Lane D. S., Cauley J. A., Khandekar J. (2012): Prospective analysis of association between use of statins or other lipid-lowering agents and colorectal cancer risk. Ann. Epidemiol. 22, 17-27 https://doi.org/10.1016/j.annepidem.2011.10.006

Steelman L. S., Franklin R. A., Abrams S. L., Chappell W., Kempf C. R., Bäsecke J., Stivala F., Donia M., Fagone P., Nicoletti F. et al. (2011): Roles of the Ras/Raf/MEK/ERK pathway in leukemia therapy. Leukemia 25, 1080-1094 https://doi.org/10.1038/leu.2011.66

Stoehr M., Mozet C., Boehm A., Aigner A., Dietz A., Wichmann G. (2014): Simvastatin suppresses head and neck squamous cell carcinoma ex vivo and enhances the cytostatic effects of chemotherapeutics. Cancer Chemother. Pharmacol. 73, 827-837 https://doi.org/10.1007/s00280-014-2412-1

Strandberg T. E., Pyorala K., Cook T. J., Wilhelmsen L., Faergeman O., Thorgeirsson G., Pedersen T. R., Kjekshus J., 4S Group. (2004): Mortality and incidence of cancer during 10-year follow-up of the Scandinavian Simvastatin Survival Study (4S). Lancet 364, 771-777 https://doi.org/10.1016/S0140-6736(04)16936-5

Thurnher M., Nussbaumer O., Gruenbacher G. (2012): Novel aspects of meval-onate pathway inhibitors as antitumor agents. Clin. Cancer Res. 18, 3524-3531

https://doi.org/10.1158/1078-0432.CCR-12-0489

Tobert J. A. (2003): Lovastatin and beyond: the history of the HMGCoA reductase inhibitors. Nat. Rev. Drug Discov. 2, 517-526 https://doi.org/10.1038/nrd1112

Tsubaki M., Fujiwara D., Takeda T., Kino T., Tomonari Y., Itoh T., Imano M., Satou T., Sakaguchi K., Nishida S. (2017): The sensitivity of head and neck carcinoma cells to statins is related to the expression of their Ras expression status, and statin-induced apoptosis is mediated via suppression of the Ras/ERK and Ras/mTOR pathways. Clin. Exp. Pharmacol. Physiol. 44, 222-234 https://doi.org/10.1111/1440-1681.12690

Ukomadu C., Dutta A. (2003): p21-dependent inhibition of colon cancer cell growth by mevastatin is independent of inhibition of G1 cyclin-dependent kinases. J. Biol. Chem. 278, 43586-43594 https://doi.org/10.1074/jbc.M307194200

van Nieuw Amerongen G. P., Vermeer M. A., Nègre-Aminou P., Lankelma J., Emeis J. J., van Hinsbergh V. W. (2000): Simvastatin improves disturbed endothelial barrier function. Circulation 102, 2803-2809 https://doi.org/10.1161/01.CIR.102.23.2803 
Vinogradova Y., Coupland C., Hippisley-Cox J. (2011): Exposure to statins and risk of common cancers: a series of nested casecontrol studies. BMC Cancer 11, 409 https://doi.org/10.1186/1471-2407-11-409

W., Prahalada S., Berry P. H., Alberts A. W., Bokelman D. L. (1988) Preclinical evaluation of lovastatin, Am. J. Cardiol. 62, 16-27 https://doi.org/10.1016/0002-9149(88)90003-3

Walker E. J., Ko A. H., Holly E. A., Bracci P. M. (2015): Statin use and risk of pancreatic cancer: results from a large, clinic-based case-control study. Cancer 121, 1287-1294 https://doi.org/10.1002/cncr.29256

Wolfe A. R., Debeb B. G., Lacerda L., Larson R., Bambhroliya A. Huang X., Bertucci F., Finetti P., Birnbaum D., Van Laere S. et al. (2015): Simvastatin prevents triple-negative breast cancer metastasis in pre-clinical models through regulation of FOXO3a Breast Cancer Res. Treat. 154, 495-508 https://doi.org/10.1007/s10549-015-3645-3

Wong W. W., Tan M. M., Xia Z., Dimitroulakos J., Minden M. D., Penn L. Z. (2001): Cerivastatin triggers tumorspecific apoptosis with higher efficacy than lovastatin. Clin. Cancer Res. 7, 2067-2075

Woschek M., Kneip N., Jurida K., Marzi I., Relja B. (2016): Simvastatin reduces cancerogenic potential of renal cancer cells via geranylgeranyl pyrophosphate and mevalonate pathway. Nutr. Cancer 68, 420-427 https://doi.org/10.1080/01635581.2016.1152383

Wu B. U., Chang J., Jeon C. Y., Pandol S. J., Huang B., Ngor E. W., Difronzo A. L., Cooper R. M. (2015): Impact of statin use on survival in patients undergoing resection for early-stage pancreatic cancer. Am. J. Gastroenterol. 110, 1233-1239 https://doi.org/10.1038/ajg.2015.217

Wu J., Wong W. W., Khosravi F., Minden M. D., Penn L. Z. (2004): Blocking the Raf/MEK/ERK pathway sensitizes acute myelogenous leukemia cells to lovastatin-induced apoptosis. Cancer Res. 64, 6461-6468 https://doi.org/10.1158/0008-5472.CAN-04-0866

Xia Z., Tan M. M., Wong W. W., Dimitroulakos J., Minden M. D., Penn L. Z. (2001): Blocking protein geranylgeranylation is essential for lovastatin-induced apoptosis of human acute myeloid leukemia cells. Leukemia 15, 1398-1407 https://doi.org/10.1038/sj.leu.2402196

Zhong G. C., Liu Y., Ye Y. Y., Hao F. B., Wang K., Gong J. P. (2016): Meta-analysis of studies using statins as a reducer for primary liver cancer risk. Sci. Rep. 6, 26256 https://doi.org/10.1038/srep26256

Zhu Y., Casey P. J., Kumar A. P., Pervaiz S. (2013): Deciphering the signaling networks underlying simvastatin-induced apoptosis in human cancer cells: evidence for non-canonical activation of RhoA and Rac1 GTPases. Cell Death Dis. 4, e568 https://doi.org/10.1038/cddis.2013.103

Zollner G., Wagner M., Fickert P., Silbert D., Fuchsbichler A., Zatloukal K., Denk H., Trauner M. (2005): Hepatobiliary transporter expression in human hepatocellular carcinoma. Liver Int. 25, 367-379 https://doi.org/10.1111/j.1478-3231.2005.01033.x

Received: April 13, 2017

Final version accepted: October 2, 2017 